Research Article

\title{
Optimization Technology of Frequency Conversion Constant Pressure Control System of Mine Emulsion Pump Station in Electrical Engineering and Automation Specialty
}

\author{
Cong Tian $\mathbb{D}^{1},{ }^{1}$ Xiwen Wei, ${ }^{1}$ Chao Yang $\mathbb{D},{ }^{2}$ and Chang $\mathrm{Su}^{2}$ \\ ${ }^{1}$ School of Electrical and Information Engineering, Heilongjiang University of Technology, Jixi 158100, Heilongjiang, China \\ ${ }^{2}$ Jieyang Institute of Technology, Guangdong University of Technology, Jieyang 522000, Guangdong, China \\ Correspondence should be addressed to Chao Yang; yangsu@dlufe-edu.cn
}

Received 8 February 2021; Revised 7 March 2021; Accepted 18 March 2021; Published 8 April 2021

Academic Editor: Sang-Bing Tsai

Copyright (c) 2021 Cong Tian et al. This is an open access article distributed under the Creative Commons Attribution License, which permits unrestricted use, distribution, and reproduction in any medium, provided the original work is properly cited.

\begin{abstract}
No matter in metal mines or coal mines, an emulsion pump station has a wide range of application market and can play an important role. In this paper, the frequency conversion constant pressure control system of the mine emulsion pump station is taken as the research object. The two kinds of water-based drawing fluids used are dispersed drawing fluid and emulsion drawing fluid. After the intelligent level of the equipment reaches a very high level, an environmentally friendly, safe, and efficient Internet of Things technology system will be added. Combined with 3D laser scanning technology based on self-scanning of road contours, the blast method is input to the terminals of the emulsion pump station for automatic blast hole positioning and semiautomation of the emulsion pump station. Combined with $5 \mathrm{~g}$ communication and other intelligent key technologies, it realizes high-end functions such as fault self-diagnosis, remote operation, and remote monitoring of the emulsion pump station and rock drill, which can be called full intelligent stage. The results show that the initial friction coefficient of drawing fluid A lubrication is 0.21 , and then, with the extension of time, the friction coefficient gradually decreases to 0.14 . The initial friction coefficient of drawing fluid $\mathrm{B}$ is 0.22 , then it decreases rapidly to 0.13 , then it is stable at 0.17 , and then it remains basically unchanged. When the temperature is $55^{\circ} \mathrm{C}$, the initial friction coefficient is 0.16 and then decreases to 0.12 . Therefore, the frequency conversion constant pressure control system of the mine emulsion pump station should be selected according to the environment and application scenarios.
\end{abstract}

\section{Introduction}

According to the development of domestic emulsion pump station technology, domestic scholars are at or above the level of imported emulsion pump stations in some research directions. Further increasing the level of automation and intelligence and upgrading to fully computer-controlled emulsion pump stations and rock drilling robots will provide economic and social benefits. From the current reports, there are good use cases in straight wall type, curved wall type, door opening type, and special-shaped excavation section. The research and application of hydraulic fracturing technology are mainly concentrated in the oil and gas industry, but the application of hydraulic fracturing technology in coal mines has been studied and discussed by researchers in the United States, Australia, and Poland.

Povarov et al. combined GIS and GMS software to analyze land subsidence [1]. Lin et al. have studied a new visual fitting method, the essence of which is from point to surface. Through the combination of the GIS and groundwater model, the visualization function of the software is more powerful [2]. Zapolnova et al. proposed a method to realize 3D discretization of geological body based on GIS. The principle of this method is to discretize an irregular geological hexahedron [3]. On the scientific discussion of frequency conversion control index reflecting journal influence through citation concentration, although Park et al. think that journals with more unbalanced citation distribution have higher influence, most studies prefer journals 
with more balanced citation distribution should have higher influence [4]. Moreover, according to Weinrich et al.'s follow-up study on the frequency conversion control index, the $\mathrm{Z}$ index shows a robust evaluation effect on both the perfectly consistent distribution of cited frequency and the highly concentrated citation distribution [5].

Davies et al. mainly studied the algorithms in MODFLOW that can make the calculation results more accurate. The results show that pcg2 and sip have better feasibility and high accuracy [6]. The research and development of the emulsion pump station and rock drill started in 1972, but it was not until 1998 that Wang et al. presided over the research and development of the emulsion pump station with automatic function and achieved a series of fruitful results [7]. Since then, Kim et al. have continued to make progress in this field and persisted in exploration [8]. Ohrem and Holden also expressed a strong desire to transform the ordinary emulsion pump station into an emulsion pump station with automatic function [9]. Landers pointed out that due to the high price of the imported emulsion pump station and higher cost of accessories and maintenance, it is conducive to the development of the mine emulsion pump station [10]. From the application status of the emulsion pump station in metal mines and coal mine roadways in China, it can be seen that there is almost no case of using automatic and intelligent rock drilling equipment. In this case, it is appropriate to adopt the way of gradual breakthrough and phased development to develop the emulsion pump station for domestic mine excavation, which can realize the basic functions first and then realize more complex functions.

This study summarizes the application status of the emulsion pump station in domestic metal mines and coal mines and quantitatively evaluates the technical advantages of the emulsion pump station in drilling accuracy, drilling efficiency, personnel safety, environmental protection index, etc. Following the strengths and weaknesses reflected in the application, some important issues to be aware of when using emulsion pump stations in road drilling engineering are summarized. Combined with the current development level of automation technology of the mine emulsion pump station, the corresponding suggestions are put forward. Finally, the shortcomings and challenges of further research and development and promotion of the mine emulsion pump station are analyzed, and the development route of the mine emulsion pump station is summarized and prospected.

\section{Intelligent Mining and Neural Network Physiological State Monitoring Technology}

2.1. Role of Emulsion Pump Station in the Project and Development Limitation. Since the late 1960s, foreign enterprises have developed, produced, and sold several generations of emulsion pump stations, basically occupying the main share of the domestic market. Large international enterprises mainly include Atlas Copco, Sandvik, etc. [11]. Due to the short $R \& D$ period in China and the strict confidentiality of design and control technology by foreign companies, the emulsion pump station developed in China lags far behind foreign countries in terms of promotion and application. The engineering and construction sector also tends to use imported goods but cannot get permission to use high-end features [12]. According to the public reports, when foreign scholars conduct scientific research, they generally use emulsion pump stations with higher automation level or directly put forward suggestions for improvement or upgrading of the problems exposed in the construction of emulsion pump stations [13]. There are few such reports in China, mainly because the mining emulsion pump station has not yet become the main tunneling equipment, and the deeper problems need to be explored [14].

The main purpose of purchasing the emulsion pump station in coal mine is to improve the single cycle footage, so the blast hole depth is often required to reach $2 \sim 2.5 \mathrm{M}$. When the wedge blasting scheme is adopted, under the premise of the same cutting angle, the distance between the blasthole and the orifice must be larger than that when the drilling depth is less than $2 \mathrm{~m}$ [15]. Because the rock drill and drill rod are installed on the thruster and the total length of the thruster can often reach $3.5 \sim 4.5 \mathrm{~m}$, the space left for the thruster to move is more narrow or even insufficient when the blast hole spacing is too wide. In serious cases, the thruster cannot move to the designated position to start drilling, or in the process of movement, the rock drill rubs and collides with the side rock, causing great economic losses [16]. Therefore, the design of the wedge cutting blast scheme requires careful selection of the appropriate cutting angle, depending on the length of the propeller of the emulsion pump station. If the cutting angle is limited, the depth of the hole will be affected. At this time, other methods such as compound wedge cutting can be selected [17]. If straight hole blasting is adopted, the influence of cutting angle is not considered. However, it is worth noting that the number of blastholes required for straight hole blasting is large, and the workload of drilling increases accordingly. Some scholars have made a lot of meaningful improvements and attempts on straight hole cutting, which is worthy of reference [18].

There are few studies on the evaluation of interdisciplinary journals of variable frequency control index at home and abroad. To solve this problem, some scholars introduce discipline standardized citation influence, consider the influence of papers of different disciplines and years on citation frequency, try to improve the calculation rules of variable frequency control index, and select the fields of library and information, materials, and electronic information with different citation behavior, which provides new ideas and methods for the frequency conversion control index and interdisciplinary journal evaluation research [19].

2.2. Advantages of Variable Frequency Constant Voltage Control System. Through the design and operation of the computer algorithm, the problems existing in the pure manual stage can be decided, predicted, and processed by the control system instead of manual work, which can reduce the task amount and error probability of workers' operation 
[20]. The control system is the core of the whole emulsion pump station. Its main function is to receive the real-time information collected by the sensor and the instructions from the computer, process the collected data, and then arrange the quantitative action of each valve group to achieve the final goal [21]. Currently, the ZYS series full computer-controlled emulsion pump station developed by CRCC Heavy Industries is in the stage of dissemination and application that can complete automatic positioning, automatic drilling, advanced geological analysis, postblasting contour reconstruction, etc. The control system plays an important role [22]. Although there are many differences between the emulsion pump station used in tunnel and the emulsion pump station used in mine excavation in terms of service conditions (such as cross-sectional area) and working environment, its successful experience is worth learning [23].

\subsection{Variable Frequency Constant Voltage Control Index} Optimization Model. According to the requirements of API Std 546-2008 "500 KVA and above brushless synchronous machines," all motors with a speed of $600 \mathrm{R} / \mathrm{min}$ and above shall be dynamically balanced in two or more planes as a complete set of components [24]. Rotors operating above the first lateral critical bending mode speed need to be balanced in at least three planes, including the central plane at or near the axial geometric center of the rotor assembly [25]. In the process of dynamic balancing, the unfiltered vibration limit value given by API Std 546-2008 is applicable to the motor with rated speed over $3000 \mathrm{R} / \mathrm{min} A_{\text {lim }}$ calculation formula is as follows:

$$
\begin{aligned}
A_{\lim } & =f(x)=\sum_{j \subset Q} c_{j} \frac{x_{j}}{\sigma\left(X_{j}^{\prime}\right)}-p, \\
N\left(d_{i}, w_{j}\right) & =P\left(d_{i}\right) P\left(w_{j} \mid d_{i}\right) ; \\
P\left(w_{j} \mid d_{i}\right) & =\sum_{k=1}^{K} P\left(w_{j}\left|z_{k}\right|\right) P\left(z_{k} \mid d_{i}\right),
\end{aligned}
$$

where $n$ is the maximum rated speed of the motor. Since the maximum rated speed of the motor in the compressor station is $4800 \mathrm{R} / \mathrm{min}$, the standard vibration limit value is $40 \mu \mathrm{M}$. Metal mines mainly include open-pit mining and underground mining. With the continuous development of high-intensity mining, a large number of large- and medium-sized open-pit mines have been transferred to underground mining. Considering the influence of the back pressure of the hydraulic support, the design spring prepressure $f t=312 \mathrm{n}$. According to experience and iterative calculation, $D 3=$ quasi $10 \mathrm{~mm}, D 1=$ quasi $11 \mathrm{~mm}$, and $D 2=$ quasi $10 \mathrm{~mm}$ are preselected. Assuming that the high pressure liquid supply pressure $\mathrm{PG}=42 \mathrm{MPa}$, then

$$
S d_{\text {gain }}(Y)=\frac{\sigma(Y)-\operatorname{avg}\left(\sigma\left(Y^{\prime}\right), \sigma\left(Y^{\prime}\right)\right)}{\sigma(Y)} .
$$

High pressure outlet control port $1234 \mathrm{p}, \mathrm{RP} 1=31.5$ mpap2 $>31.5 \mathrm{MPa}$, high pressure inlet control port pressure:

$$
\begin{aligned}
& C(k)= {\left[\zeta_{1} c_{1}(t)+\zeta_{2} c_{2}(k)+\zeta_{3} c_{3}(k)+\zeta_{4} c_{4}(k)\right.} \\
&\left.+\zeta_{5} c_{5}(k)+\zeta_{6} w_{i k}\right], \\
& c_{1}(t) \geq 0, \\
& c_{2}(k) \geq 0, \\
& c_{3}(k) \geq 0, \\
& c_{4}(k) \geq 0, \\
& c_{5}(k) \geq 0 .
\end{aligned}
$$

MPA by changing the diameter $D 1$ of rod seal and the diameter I2 of sealing surface, the criterion for selecting the best splitting point is defined as $S d$, expressed as

$$
\begin{aligned}
S d= & \min w_{k}(t)=\left[\omega_{1}\left(\frac{d_{k}}{V}\right)+\omega_{2}\left(\frac{d_{k}}{V}\right)+\omega_{3}\left(\frac{d_{k}}{V}\right)\right. \\
& \left.+\omega_{1}\left(P_{K} T_{K}\right)\right], \\
\vartheta & =\frac{2 k}{k+1}+\frac{2 c_{1}+c_{2}+3 e t-2 e t \zeta}{3} .
\end{aligned}
$$

Therefore, the corrected vector should also be rotated by the same angle $\theta$ to eliminate the unbalance of the motor. This method can quickly and effectively find the imbalance of the rotor, reduce the times of counterweight, and improve the accuracy of dynamic balance. Taking the dynamic balance test of an electric compressor station as an example, Bentley ADRE vibration measuring instrument was used to lead out 7path displacement signal and key signal from BNC interface in front of the vibration protection system. The vibration measuring instrument transmits the received signal to the computer and displays and analyzes the vibration data through adre analysis software on the computer. The displayed data include vibration value, gap voltage, amplitude and phase of 1-fold frequency, and amplitude and phase of 2fold frequency:

$$
\begin{aligned}
(\operatorname{In}-\alpha W) y & =(\operatorname{In}-\alpha W) X \beta+\varepsilon, \\
\wp_{\kappa} & =\frac{2 k}{k+1}+\left[\frac{1}{2}+\frac{1}{2 k}\right]\left[\frac{c_{2}-c_{1}}{3}\right]^{2}+\frac{2\left(c_{2}-c_{1}\right)}{3}, \\
\psi & =\sum_{x=1}^{\theta} V x=\sum_{x=1}^{9}\left(\frac{W x}{\sum_{1}^{n} W_{\mathfrak{J}}} S x\right) .
\end{aligned}
$$

Since the unbalance is mainly reflected in the frequency doubling, the amplitude and phase of the frequency doubling are mainly concerned during the dynamic balance test, and the vibration analysis is carried out through the Bode diagram. In the field test, the motor should be operated for the first time and warmed up for 20 minutes at $600 \mathrm{R} / \mathrm{min}$ and $1200 \mathrm{R} / \mathrm{min}$, respectively. When the speed reaches $2000 \mathrm{r} / \mathrm{min}$, the vibration value of the motor is measured, and 
it is found that the vibration value of the $x$-axis at the shaft extension end of the main motor is larger. The Bode diagram of the vibration spectrum is used to read the relevant vibration data: the vibration value of 1 -fold frequency is $117 \mu$ $\mathrm{m}$, and the phase angle is 37 degrees:

$$
\begin{array}{r}
\Delta Q_{L}+\Delta Q_{S}+\Delta Q_{R}=\Delta Q, \\
w_{i k}=\sum_{a}^{n} \tau_{1} X_{i k}+\sum_{b}^{n} \tau_{2} U\left(Y_{i k}\right)+B_{i k} .
\end{array}
$$

After the motor is shut down for the first time, a $75 \mathrm{~g}$ counterweight is added at the $90^{\circ}$ position of the main motor shaft extension end. Restart the motor for running test, when the motor speed reaches $2000 \mathrm{r} / \mathrm{min}$, the first harmonic vibration value of the main motor shaft extension end is $94.4 \mu \mathrm{m}$, and the phase angle is 78 degrees:

$$
\begin{aligned}
I & =f\left(W^{e} D_{1}+\delta^{e}\right), \\
D_{a} & =g\left(W^{d} I+\delta^{d}\right), \\
w_{G}^{A_{i} A_{j}} & =\max \left\{0, W_{G} \cdot \varepsilon\left(f_{G}^{A_{i}}, f_{G}^{A_{j}}\right)\right\},
\end{aligned}
$$

where $I$ is the output result after decoding, and the training objective of self-encoder is to reduce the error between reconstruction and initial value by optimizing parameters. Usually, mean square error (MSE) is used as the loss function to quantify the deviation between the reconstructed data and the original input data. The mean square error is calculated as follows:

$$
\begin{aligned}
\operatorname{MES}\left(y, y^{\prime}\right) & =\frac{\sum_{i=1}^{m}\left(y_{i}-y_{i}^{\prime}\right)}{m}, \\
L_{r} & =\left\|D_{I}-D_{O}\right\|_{2} .
\end{aligned}
$$

According to the vector diagram of the unbalance of the compressor station motor after adding the counterweight, the vector $A 1$ is 117 unit length and the angle is 37 degrees, and the vector $A 2$ is 94.4 unit length and the angle is 78 degrees. Using the vector triangle rule, draw the vector triangle, so as to find the length of vector $A 3$ is 77 unit length. From this, the mass of counterweight should be $104 \mathrm{~g}$, and the angle between vector $A 2$ and vector $A 3$ is $55^{\circ}$ measured. Therefore, the configuration block at $90^{\circ}$ position should be offset by $55^{\circ}$ again; that is, a counterweight block with a mass of $104 \mathrm{~g}$ should be added at $145^{\circ}$ position:

$$
\begin{aligned}
f_{R}^{A_{i}} & =w_{G}^{A_{i} A_{j}} \cdot V \\
P\left(d_{i}, w_{j}\right)= & P\left(d_{i}\right) P\left(w_{j} \mid d_{i}\right) ; P\left(w_{j} \mid d_{i}\right) \\
= & \sum_{k=1}^{K} P\left(w_{j} \mid z_{k}\right) P\left(z_{k} \mid d_{i}\right), \\
\lambda(A i, A j)= & {\left[\log \left(\frac{\left|x_{A_{i}}-a_{A_{j}}\right|}{w_{A_{j}}}\right), \log \left(\frac{\left|y_{A_{i}}-y_{A_{j}}\right|}{h_{A_{j}}}\right),\right.} \\
& \left.\log \left(\frac{w_{A_{i}}}{w_{A_{j}}}\right), \log \left(\frac{h_{A_{i}}}{h_{A_{j}}}\right)\right] .
\end{aligned}
$$

After adding the counterweight test, make the motor run for the third time, and carry out the dynamic balance test. When the motor runs to $2000 \mathrm{r} / \mathrm{min}$, it is found that the vibration value of the dynamic balance is $31.9 \mu \mathrm{m}$, and the phase angle is $124^{\circ}$ which is lower than the vibration limit value of $40 \mu \mathrm{M}$. The dynamic balance test is completed.

\section{Optimization Technology of Frequency Conversion Constant Pressure Control System of Mine Emulsion Pump Station}

3.1. Objects. In this paper, the frequency conversion constant pressure control system of the mine emulsion pump station is taken as the research object. The two kinds of water-based drawing fluids used are dispersed drawing fluid and emulsion drawing fluid. The main components of the two kinds of drawing fluids are base oil, antiwear agent, antirust agent, antifriction agent, and $\mathrm{pH}$ regulator. The biggest difference is that the dispersed drawing fluid disperses polymer particles into the emulsion, while the emulsion drawing fluid does not contain polymer particles. The particle size of the polymer particles in the dispersion stretching liquid is 34.8 to $3179 \mathrm{~nm}$. The size of the particles dispersed in the emulsion is not uniform because the polymer tends to aggregate. The particle size of emulsion drawing fluid is $44.1 \sim 289.3 \mathrm{~nm}$. The concentration of drawing solution is $5 \%$. The drawing die is made of cemented carbide, and the material of steel cord is $82 \mathrm{x}$ high carbon steel. The diameter of steel cord is $3.0 \mathrm{~mm}$. After 19 22 passes, the diameter of steel cord is pulled to about $0.2 \mathrm{~mm}$, and the deformation of each pass is about $15 \%$.

3.2. Steps of Model Checking. After the intelligent level of equipment reaches a very high level, a green, safe, and efficient mine Internet of Things technology system will be added. Currently, research and development of mine emulsion pump stations is in the process of jumping from a purely manual stage to a semiautomatic and fully automatic stage. The purely manual phase requires manual intervention by the operator, even if the emulsion pump station is used for drilling and blasting drilling in many projects. This is the same as replacing the production tools in the hands of the worker. Although the drilling speed and straightness of the blast hole have been improved, the accuracy of positioning and the control of drilling angle still need the assistance of surveying and mapping personnel, which not only has a heavy workload but also has a limited effect. In addition, in the process of moving the boom, the drilling sequence selected by the operator is often not the optimal sequence, and it is necessary to ensure that multiple booms and the rock wall will not collide. When encountering the sticking problem, we can only rely on the rich operation experience of the old staff, manually adjust the ROP, or even repeatedly knock the drill rod to solve it, and then establish the emulsion pump station through the following steps: 
(1) The development of the mining hydraulic emulsion pump station with high assembly accuracy is convenient for pure manual operation.

(2) Combined with 3D laser scanning technology, based on the self-scanning of roadway contour, the blasting scheme is input into the terminal of the emulsion pump station to realize the automatic positioning of blasting hole and the semiautomation of the emulsion pump station.

(3) Centralized management and control by the emulsion pump station control terminal solves the problems of autonomous walking, automatic positioning, posture control, etc., realizes the multi boom hole sequence planning of the emulsion pump station, automatic drilling of rock drill, automatic drill changing, etc., and realizes the full automation of the emulsion pump station.

(4) Under the premise of stable operation of basic functions such as automatic positioning + automatic drilling, combined with intelligent key technologies such as $5 \mathrm{~g}$ communication, high-end functions such as fault self-diagnosis, remote operation, and remote monitoring of the emulsion pump station and rock drill are realized, which can be called full intelligent stage.

On the other hand, automation and application of intelligent technology at emulsion pump stations need to solve many complex problems and many practitioners in blasting, mine construction, automation, machinery, and other areas have: you need to do participate, cooperate, and coordinate with each other. The lack of any of these links will lead to the operator's poor experience in the use process, resulting in highly intelligent products being abandoned on-site. On the other hand, due to the domestic emulsion pump station automation and other related technologies still have room for further improvement and the advent of a mature product, it is necessary to go through constant polishing and correction. Designers and users should keep enough patience to innovate and verify through a lot of investment and enough experiments.

\section{Optimization Technology Analysis of Frequency Conversion Constant Pressure Control System of Mine Emulsion Pump Station}

As shown in Figure 1, the liquid supply pressure of the emulsion pump station in the main system of the liquid supply system is $31.5 \mathrm{Mpa}$, which supplies liquid to the hydraulic control check valve of the column. When the liquid supply pressure of the emulsion pump station (or other pressure source) of the auxiliary system is greater than 31.5 Mpa (generally $42 \mathrm{MPa}$ ), it supplies liquid to the booster switching valve of column bypass separately. In the process of hydraulic support rising, when the pressure in the lower chamber of the column reaches a certain value, the main electrohydraulic valve of the support controls the plug-in one-way valve core of the bypass boost switching valve to open. At this time, the ultrahigh pressure fluid supplied to the bypass boost valve enters the lower chamber of the column and pressurizes the lower chamber of the column. When the liquid pressure in the lower chamber of the column increases to the liquid supply pressure of the emulsion pump station (or other pressure source) of the auxiliary system, under the control of the electrohydraulic control main valve of the support, close the cartridge check valve core of the bypass booster switching valve, and stop the liquid feeding into the lower chamber of the column, so as to increase the initial support force of the column.

The friction coefficient curve of cemented carbide ball/ brass disc is shown in Figure 2. When the temperature is $25^{\circ} \mathrm{C}$, the initial friction coefficient of drawing fluid $\mathrm{B} \mathrm{lu}-$ brication is 0.175 , and then, with the extension of time, the friction coefficient gradually decreases to 0.15 . The initial friction coefficient of drawing fluid lubrication is 0.165 , and then it decreases rapidly to 0.145 and then basically remains unchanged. When the temperature is $60^{\circ} \mathrm{C}$, the initial friction coefficient is 0.16 and then decreases to 0.11 . The friction coefficient of drawing fluid A was 0.145 at first, then decreased to 0.12 , and increased to 0.14 with the extension of friction time. At two experimental temperatures, the initial friction coefficient of drawing fluid B is higher than that of drawing fluid A.

The schematic diagram of double circuit liquid supply is shown in Figure 3. The lower chamber of the column is supplied by the double circuit liquid supply system. The main system supplies liquid to the column hydraulic control check valve after the electrohydraulic control reversal main valve, and the other is used as the pilot control liquid for the bypass pressurization switching valve check valve and bypass pressurization switching valve. This design can prevent the liquid in the lower chamber of the column from flowing back into the system when the roof comes to pressure. It causes the column to sink and the support strength to decrease. The one-way valve of bypass pressurization switching valve adopts the steel to steel hard sealing form, which increases the service life and sealing performance, so as to meet the requirements of the initial support force of the column.

As shown in Table 1, the station is equipped with filter separator, flow meter, compressor unit, and other related equipment and facilities, which can realize the functions of natural gas filtration, metering, pressurization, pressure regulation, and distribution. The main equipment of the station is four U.S. electric driven centrifugal compressor units, with pcl803 model, $20 \mathrm{MW}$ power, and $26728 \mathrm{~m}^{3} / \mathrm{min}$ rated flow. The power of synchronous variable frequency motor is $20 \mathrm{MW}$, and rated speed is $4800 \mathrm{R} / \mathrm{min}$, which is produced by Shanghai Electric Machinery Factory. The inverter model NC HVVF 10/10-23000SLO is produced by Shanghai Nengke Electric Co., Ltd. Therefore, the motor and other related equipment play an important role in the safe operation of the compressor unit and the stable transmission of oil and gas. In the field dynamic balance test, due to the lack of dynamic balance professional equipment, we have to use the vibration sensor installed on the motor for data collection and get the motor unbalance through vibration 


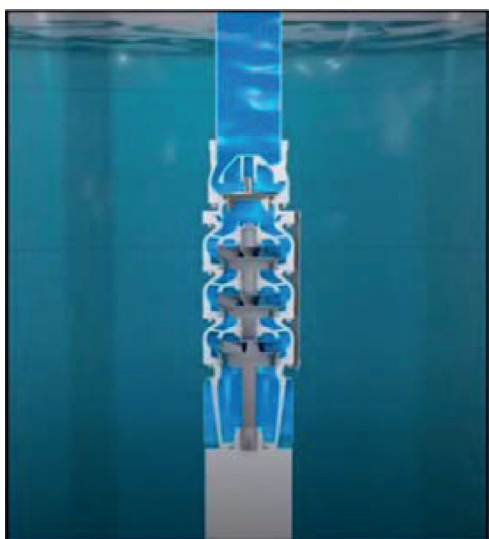

(a)

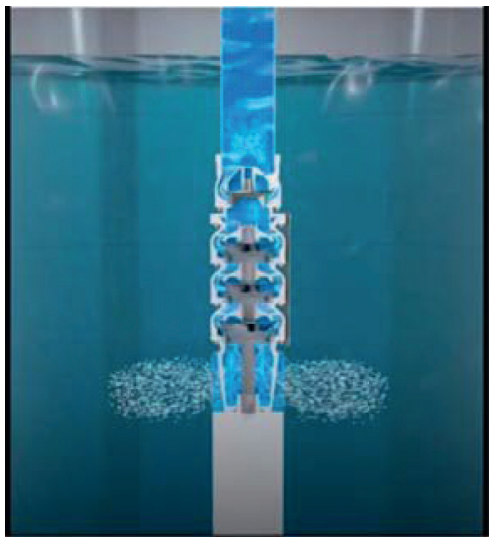

(d)

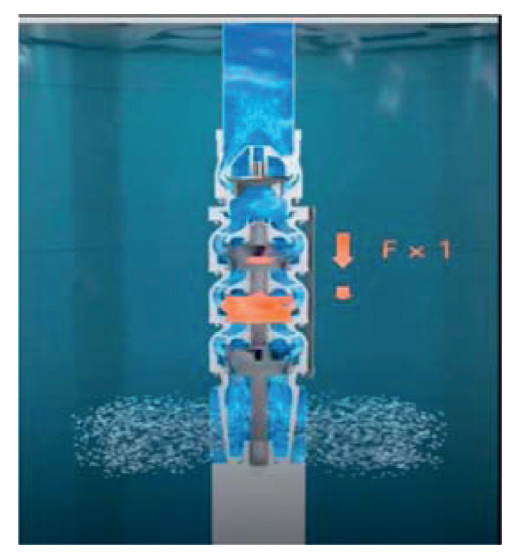

(b)

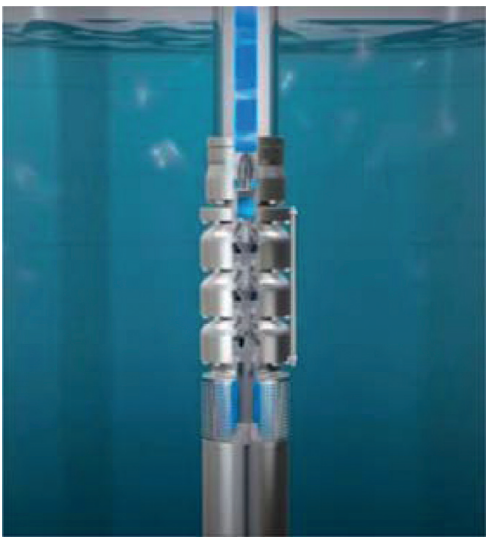

(e)

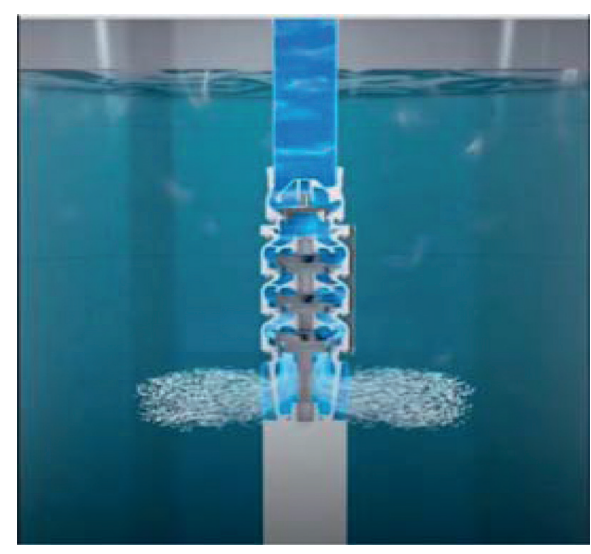

(c)

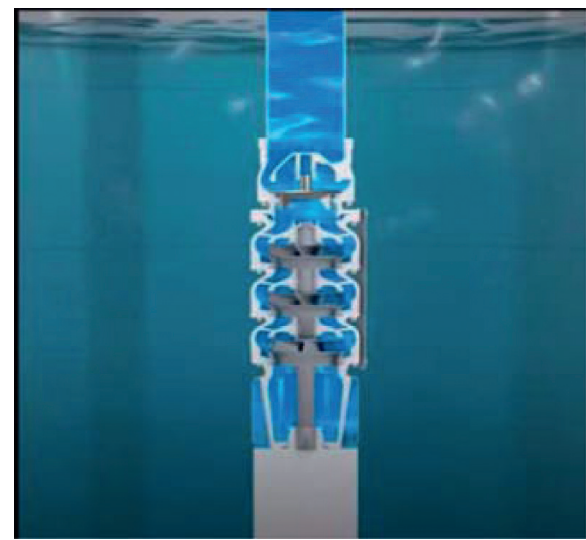

(f)

Figure 1: Lifting process of hydraulic support (from Google: http://1il50.cn/I3wI1).

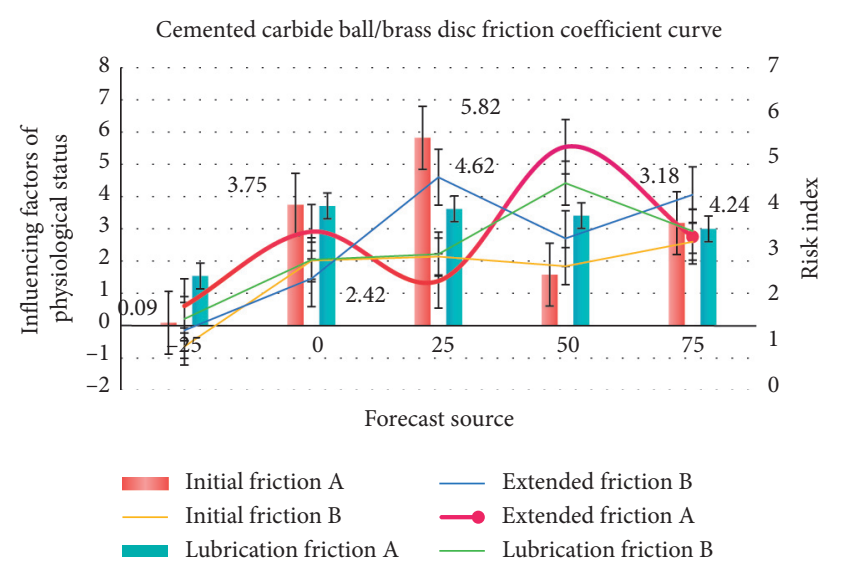

FIgURE 2: Cemented carbide ball/brass disc friction coefficient curve.

analysis. The motor dynamic balance test of the Heihe compressor station is to use the vector method, add the counterweight at the corresponding position, calculate the rotor unbalance by drawing, adjust the motor dynamic balance, and make the motor vibration value meet the standard requirements.

As shown in Figure 4, the initial friction coefficient of drawing fluid A lubrication is 0.2 , and then, with the extension of time, the friction coefficient gradually decreases to 0.13 . As shown in Table 2, the initial friction coefficient of drawing fluid $B$ is 0.22 , then it drops to 0.14 quickly, then it is stable at 0.15 , and then it remains basically unchanged.

After the cemented carbide ball/brass disc friction test, the wear marks on the brass disc of the variable frequency constant pressure control system of the emulsion pump station are shown in Figure 5. It can be seen from the figure that the wear marks obtained by using drawing fluid lubrication are much larger than those obtained by using drawing fluid lubrication. Furthermore, SEM was used to observe the micromorphology of the wear scar area, as shown in Figure 5(a). It can be seen that the surface of the wear scar lubricated with drawing fluid is smooth, and there is no obvious corrosion pit, but there is scratch mark. The surface of the wear scar area lubricated by drawing fluid is rough, and there are obvious traces of plastic flow along the shear direction and a large number of corrosion pits. This kind of surface morphology is helpful to enhance the adhesion between rubber and copper surface. In the study, the surface of dual face cemented carbide ball of friction pair was observed, as shown in Table 3.

As shown in Figure 6, there are many black spots on the surface of the ball lubricated with drawing fluid. EDS analysis showed that $\mathrm{Cu}$ peak with high intensity could be seen in the black spot area. This indicates that the wear debris 


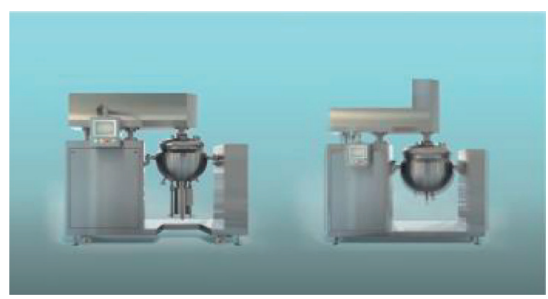

(a)

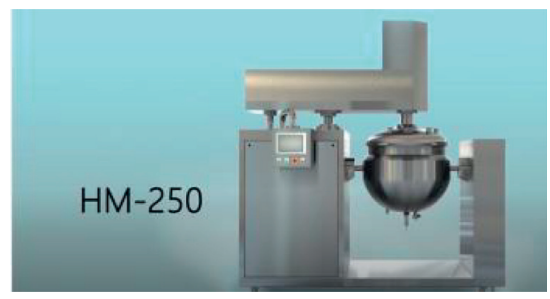

(d)

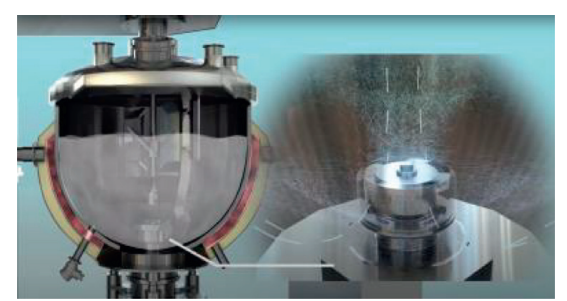

(b)

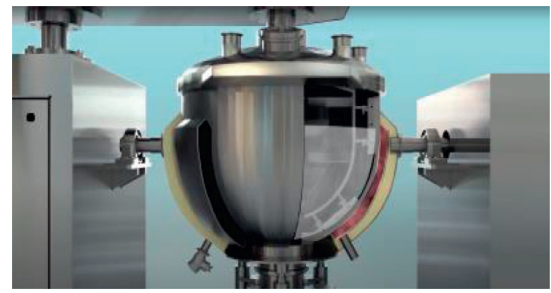

(e)

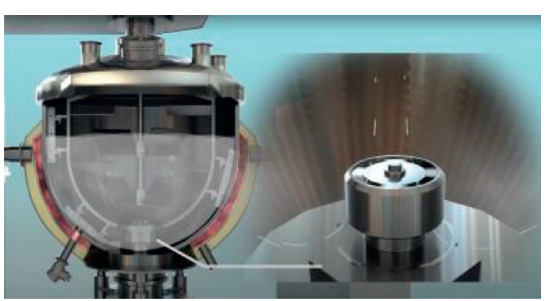

(c)

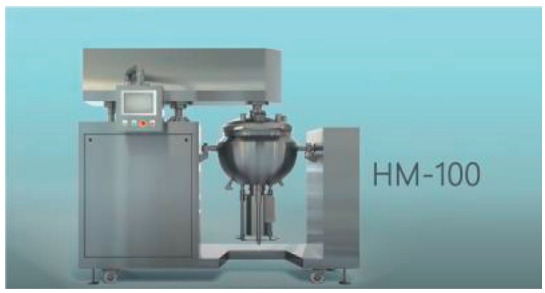

(f)

FIGURE 3: Schematic diagram of dual-circuit liquid supply (from INORA, https://www.inora.com/).

TABLE 1: Related equipment and facilities in the station.

\begin{tabular}{lcccccc}
\hline Temperature & Initial friction A & Extended friction A & Lubrication friction A & Initial friction B & Extended friction B & Lubrication friction B \\
\hline-25 & 0.09 & 1.83 & 1.54 & 0.95 & 1.3 & 1.55 \\
0 & 3.75 & 3.44 & 3.71 & 2.81 & 2.42 & 2.83 \\
25 & 5.82 & 2.37 & 3.62 & 2.9 & 4.62 & 2.95 \\
50 & 1.58 & 5.28 & 3.41 & 2.69 & 3.29 & 4.49 \\
75 & 3.18 & 3.33 & 3 & 3.22 & 4.24 & 3.45 \\
\hline
\end{tabular}

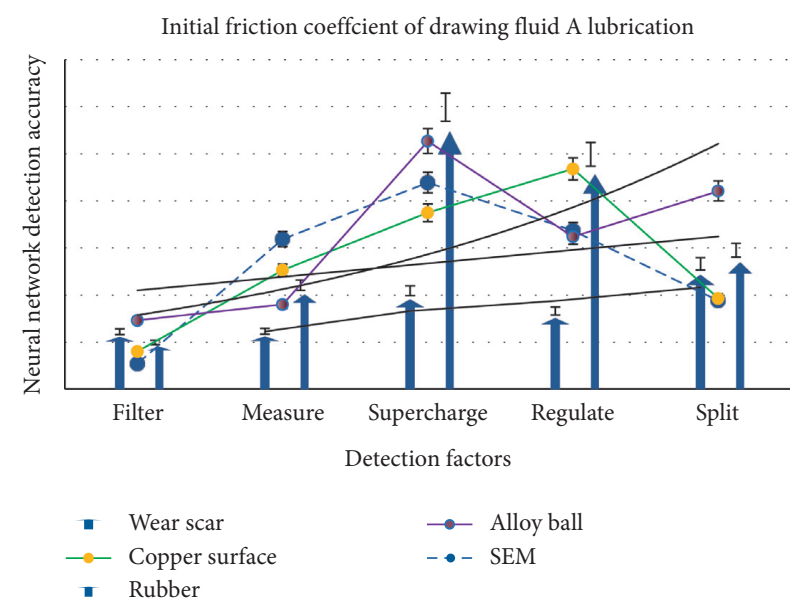

FIGURE 4: Initial friction coefficient of drawing fluid A lubrication.

generated by the brass sample is adsorbed on the surface of the ball during the friction process, forming the material transfer. For the case of using drawing fluid lubrication, there are only a few black spots on the surface of the ball, and the energy spectrum analysis also shows that only a small amount of $\mathrm{Cu}$ is detected on the surface of the ball. This shows that the drawing fluid can inhibit the material transfer between the two friction pairs.

After the friction test of brass wire/diamond plate, the wear marks on diamond plate were observed by
TABle 2: Change of friction coefficient of drawing fluid $B$ lubrication.

\begin{tabular}{lccccc}
\hline Item & Filter & Measure & Supercharge & Regulate & Split \\
\hline Scar & 1.42 & 0.4 & 1.68 & 1.03 & 1.23 \\
SEM & 2.93 & 2.46 & 1.85 & 2.56 & 1.93 \\
Rubber & 2.9 & 2.65 & 5.44 & 5.87 & 4.64 \\
Surface & 4.56 & 4.28 & 2.06 & 1.59 & 1.3 \\
Alloy ball & 4.29 & 3.16 & 1.54 & 2.73 & 3.68 \\
FEI & 2.14 & 2.59 & 4.18 & 2.71 & 4.27 \\
\hline
\end{tabular}

backscattered electron image of scanning electron microscope, as shown in Table 4 . It can be seen from the table that the amount of copper sticking on the surface wear marks lubricated by drawing fluid is much more than that lubricated by drawing fluid. Furthermore, EDX was used to analyze the composition of wear marks of polycrystalline disks. It can be seen that similar results were obtained in the experiments of cemented carbide ball/brass disk and brass wire/polycrystalline diamond disk. That is to say, although the friction coefficient of drawing fluid is slightly higher than that of drawing fluid, there is less brass adhesion on the dual surface contacting with brass, which indicates that drawing fluid can be used, in order to restrain the adhesion and material transfer between the surfaces of the friction pair.

As shown in Figure 7, the results of field drawing experiment of the emulsion pump station show that the broken wire rate of dispersed drawing fluid is much higher than that 


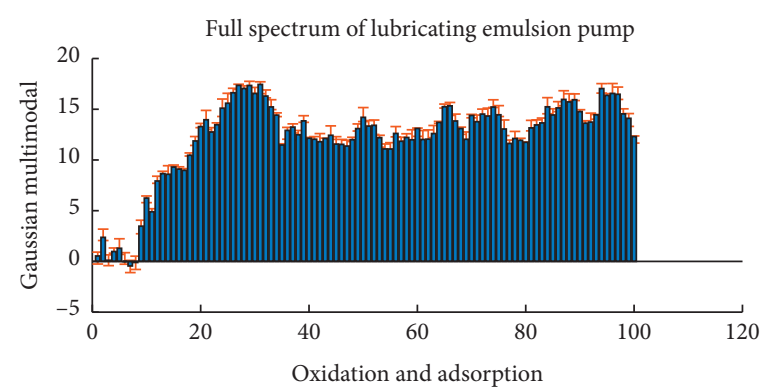

Brass alloy

(a)

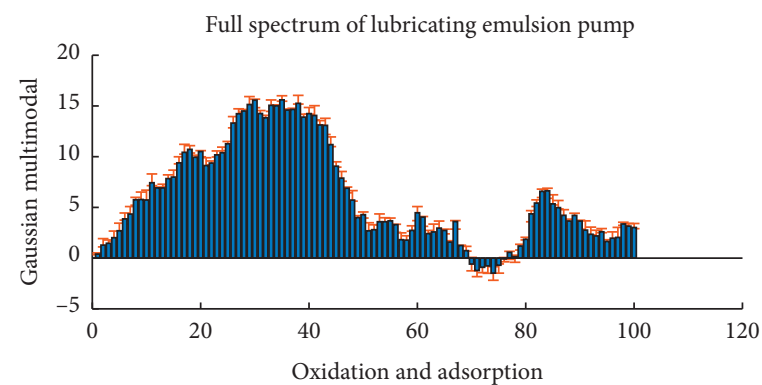

Brass alloy

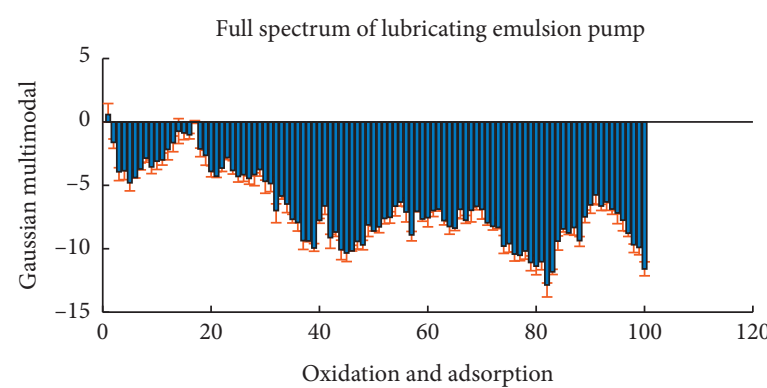

Brass alloy

(b)

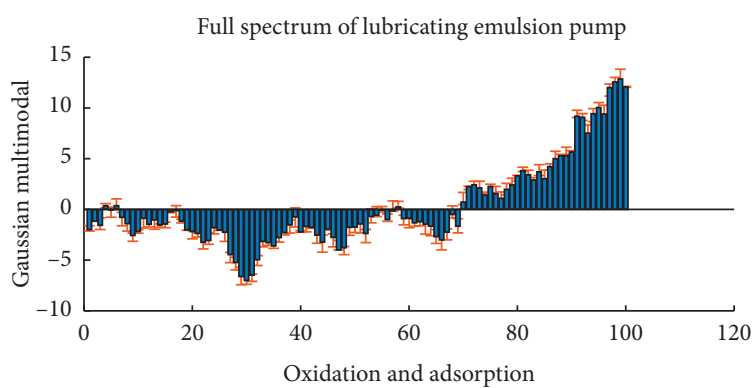

Brass alloy

(c)

(d)

FiguRE 5: Wear scars on the brass plate of the frequency conversion constant pressure control system.

TABle 3: Carbide ball surface of the dual surface of the friction pair.

\begin{tabular}{|c|c|c|c|c|c|}
\hline Item & Wear scar & SEM & Rubber & Copper surface & Alloy ball \\
\hline Filter & 1.22 & 0.54 & 0.99 & 0.8 & 1.46 \\
\hline Measure & 1.23 & 3.19 & 2.21 & 2.53 & 1.8 \\
\hline Supercharge & 2.09 & 4.39 & 5.99 & 3.75 & 5.27 \\
\hline Regulate & 1.66 & 3.37 & 4.99 & 4.68 & 3.24 \\
\hline Split & 2.66 & 1.88 & 2.95 & 1.93 & 4.21 \\
\hline
\end{tabular}

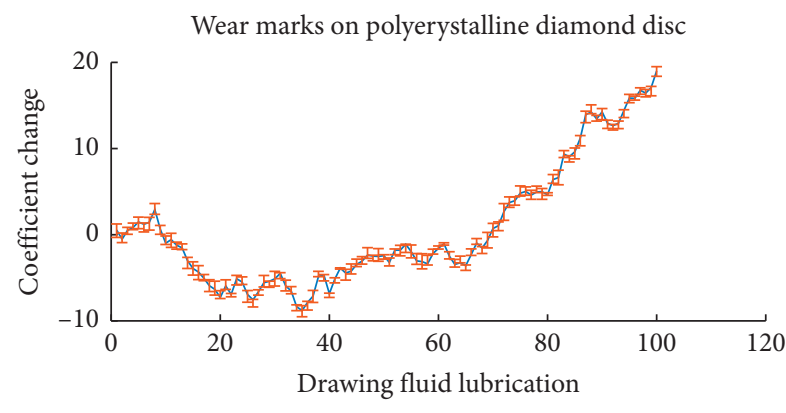

Coefficient A

(a)

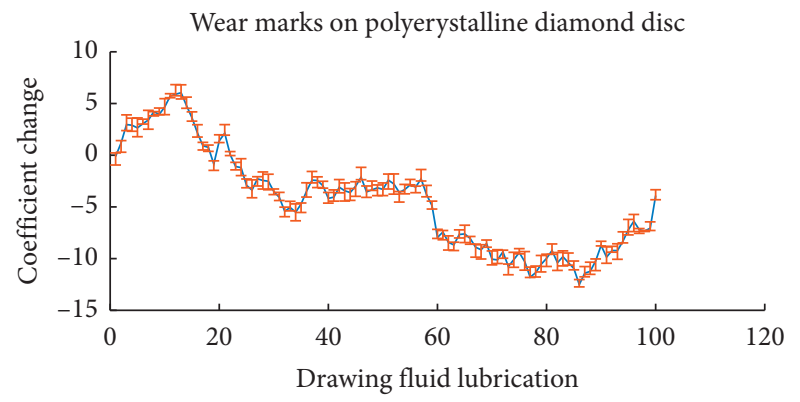

(c)

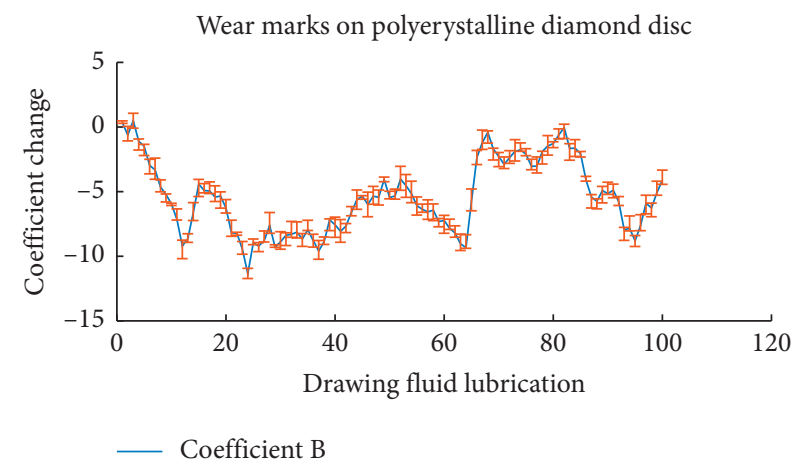

(b)

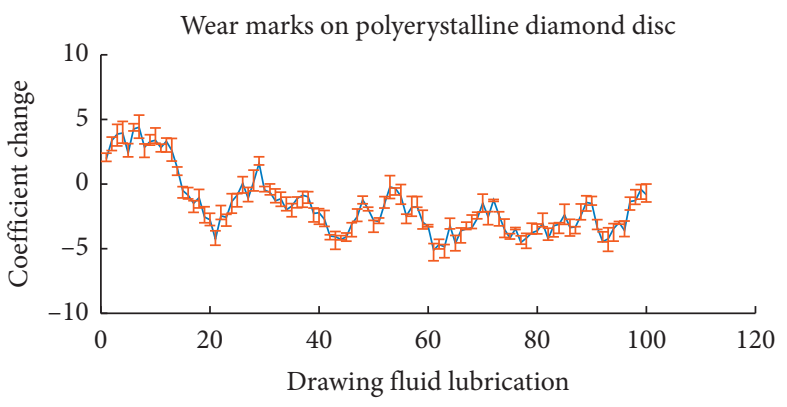

(d)

FIgURE 6: Ball surface lubricated with drawing fluid. 
TABLe 4: Wear marks on polycrystalline diamond disc.

\begin{tabular}{lccccc}
\hline Item & Wear scar & SEM & Rubber & Copper surface & Alloy ball \\
\hline Filter & 1.22 & 0.54 & 0.99 & 0.8 & 1.46 \\
Measure & 1.23 & 3.19 & 2.21 & 2.53 & 3.8 \\
Supercharge & 2.09 & 4.39 & 5.99 & 4.75 & 5.27 \\
Regulate & 1.66 & 3.37 & 4.99 & 1.68 & 3.24 \\
Split & 2.66 & 1.88 & 2.95 & 1.93 & 4.21 \\
\hline
\end{tabular}

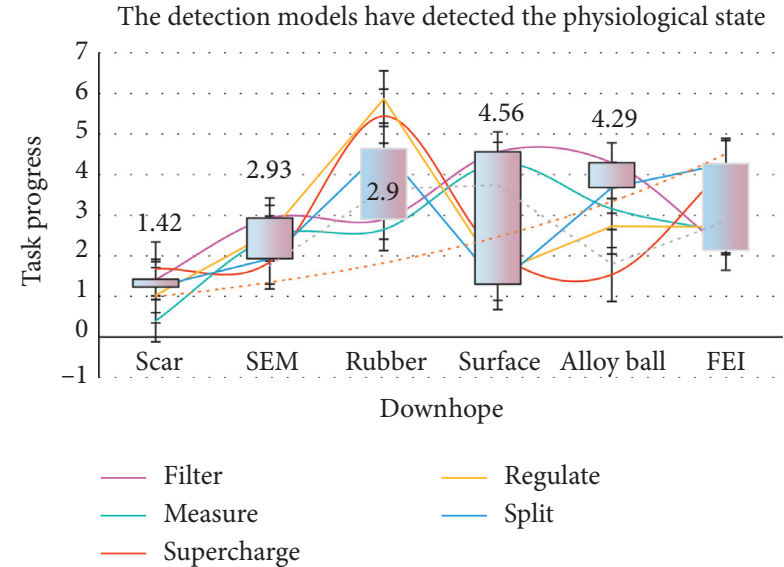

FIGURE 7: On-site drawing experiment of the emulsion pumping station.

of emulsion drawing fluid. In addition, when the adhesive strength between the drawn steel cord and the rubber was tested, it was found that the adhesive strength between the steel cord and the rubber was better when the drawn liquid was used than when the drawn liquid was used. Samples were taken from broken steel cords drawn with various drawing fluids to analyze the cause of the break. After ultrasonic cleaning with ethanol and acetone for 15 minutes, the samples were dried and used for various analytical tests. The surface microstructure of steel cord was observed by scanning electron microscope Fei quanta200 FEG (SEM), and the surface composition of steel cord was analyzed by energy dispersive spectrometer (EDS).

The internal pneumatic rock drill and emulsion pump station coexist all the time, and there is no obvious trend to replace each other. However, no matter what kind of tunneling equipment is used, the single cycle footage is on the rise. As shown in Figure 8, the overall footage of the emulsion pump station is higher than that of pneumatic rock drill. This is because the drilling rod of the emulsion pump station is longer. For example, Atlas Boomer 281 is often equipped with $3.7 \mathrm{~m}$ long drilling rod, while Atlas Boomer 282 can be equipped with $5 \mathrm{~m}$ long drilling rod, and the drilling depth is generally $3.2 \sim 3.7 \mathrm{~m}$. Compared with the $2.2 \mathrm{~m}$ or $3 \mathrm{M}$ long drill rod used by yt- 28 and other pneumatic rock drills, the blast hole depth is generally less than $2.5 \mathrm{~m}$. In general, the emulsion pump station has obvious advantages. Compared with the data of cross section shape and size, the cross section of the drilled roadway is mainly straight wall arch, occasionally rectangular, or special-shaped roadway.

As shown in Figure 9, in other conditions, especially in the same mine with the same lithology, only replacing the drilling equipment can achieve better operation effect. This study takes the literature as a specific case for further analysis of potential technical benefits of using emulsion pump stations on metal mining roads. During the process of excavating hard rock roads at the Samurai Iron Mine in Anhui Province, the hardness and impedance characteristics of the rocks are high, so the supervision coefficient reaches 12-18, and the excavation efficiency and blasting efficiency are low. The results are poor in drilling speed, explosive consumption, drilling workload, and surrounding rock forming quality. The size of the introduced tunneling equipment Atlas Boomer 281 is $10.7 \mathrm{~m} \times 3.1 \mathrm{~m} \times 2.8 \mathrm{~m}$, and the total length of the drill pipe is $3.7 \mathrm{~m}$. In the $3.8 \mathrm{~m}$ wide roadway, it is relatively large. Similar to other cases, the straight hole and empty hole cutting scheme is selected, and the blast hole depth is designed to be $2.8 \mathrm{~m}$, while the field statistics show that the drilling time of single blast hole is $2 \sim 3 \mathrm{~min}$. In order to ensure the quality of drilling, the method of manually marking the blast hole position in advance is adopted. It is proved from the side that even in metal mines, it still needs time investment and technology accumulation to achieve the goal of tunneling automation.

As shown in Figure 10, but from the perspective of section size, the roadway where the emulsion pump station is located is often wider, generally $4.8 \mathrm{~m}$ or more. However, the width of the tunnel with pneumatic rock drill is usually $3 \sim 4 \mathrm{~m}$, and there are a lot of cases with the width less than $2 \mathrm{~m}$. It can be seen that when purchasing the emulsion pump station, the matching degree of its external dimension and operation range with the excavation section should be considered, so as to give full play to the role of machinery. Because there are a large number of tunnels with small cross section size in metal mines and there is no alternative emulsion pump station with small size when driving, it is bound to continue to use manual hand-held equipment for drilling operation for a long time. If conditions permit, for example, when the section size of roadway is larger than $4 \mathrm{~m} \times 4 \mathrm{~m}$, the emulsion pump station can be considered. In order to improve underground production efficiency and mechanized operation level, Songxianshan Gold Mine plans to popularize the use of the emulsion pump station and compares the application effect of the emulsion pump station and pneumatic rock drill. 


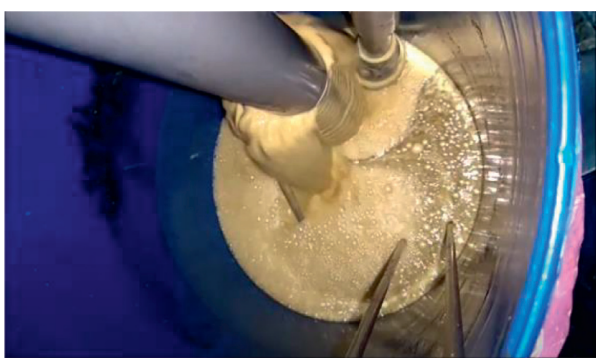

(a)

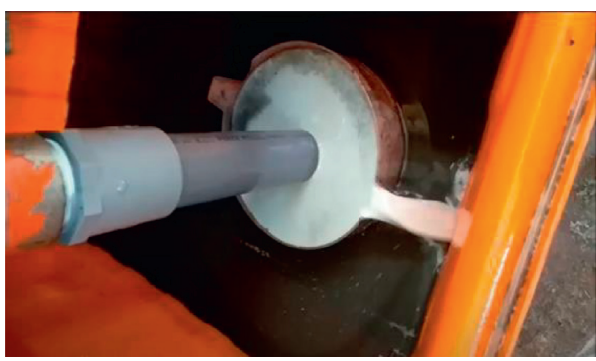

(c)

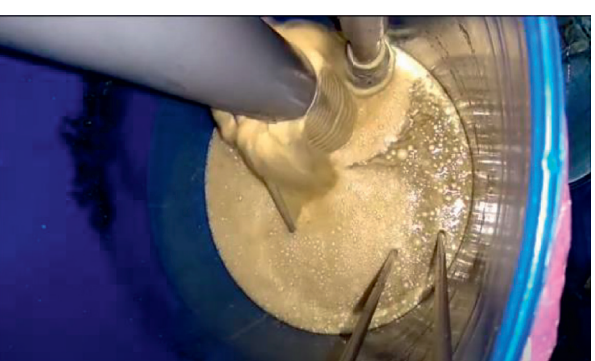

(b)

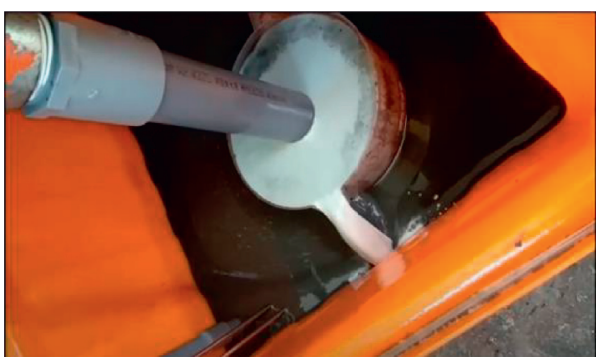

(d)

FIGURE 8: Emulsion pumping station is higher than when using pneumatic rock drill (from Google: https://www.youtube.com/watch? $\mathrm{v}=\mathrm{xFVJly6ViSo})$.

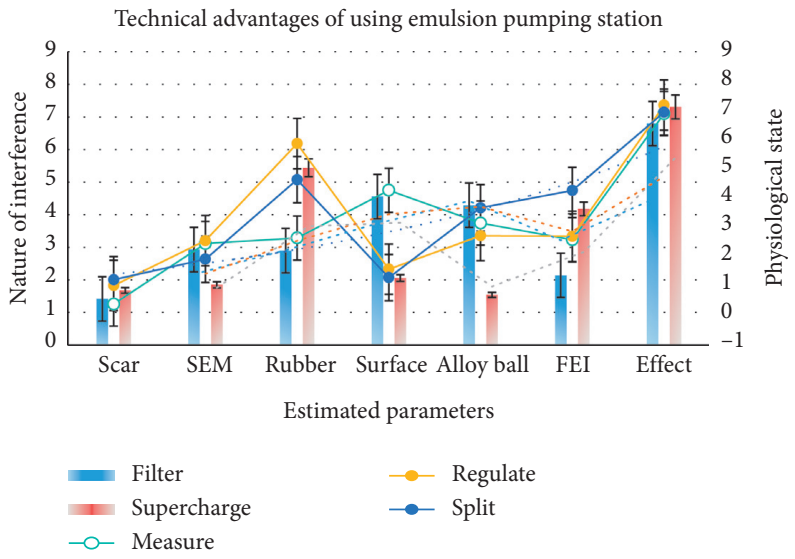

FIgURE 9: Technical advantages of using the emulsion pumping station.
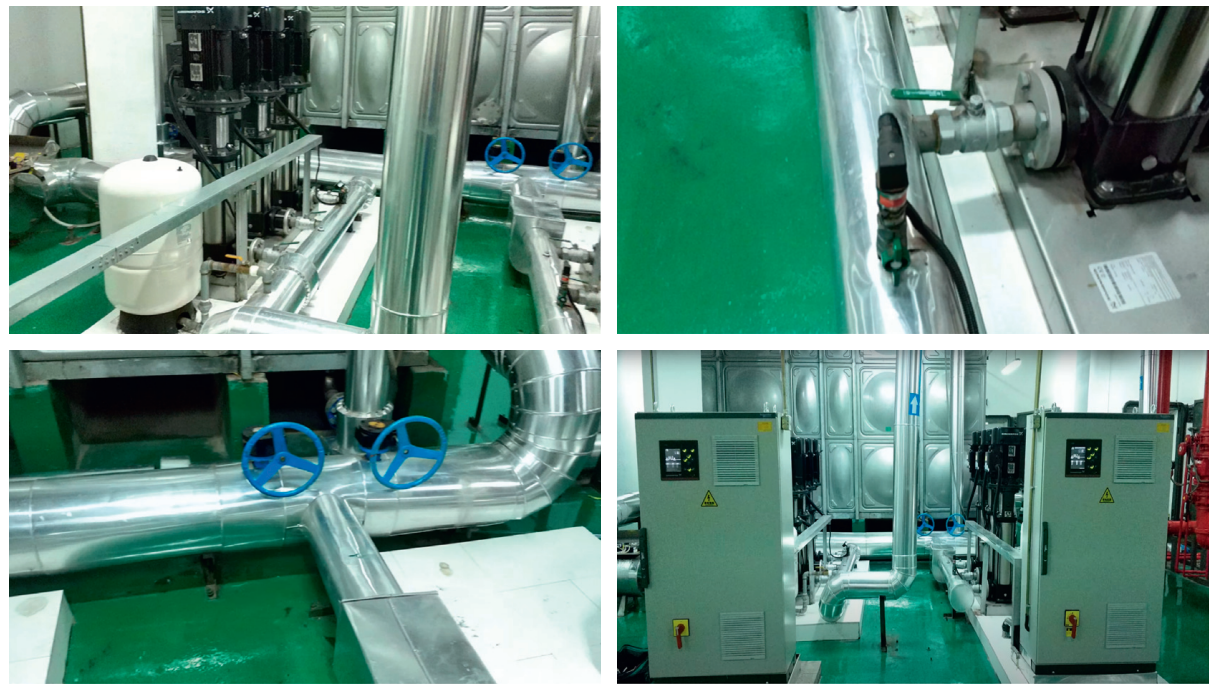

FIGURE 10: Real scene shooting picture of the emulsion pump station (from Google: http://1il50.cn/NiR97). 


\section{Conclusions}

With the improvement of safety requirements and environmental awareness, some mining enterprises have gradually introduced large automation equipment such as emulsion pump station to replace the manual extensive operation mode. At the same time, the industry is also seeking to further develop automatic mining mode into intelligent mining mode. For the mine which needs to use drilling and blasting method to achieve the purpose of tunneling, the digital and intelligent emulsion pump station can achieve the purpose of high precision, high efficiency, safety, and economy. The emulsion pump station is largescale tunneling equipment which is mainly used for drilling blast hole and anchor hole in the drilling and blasting of roadway and tunnel. According to the size of the driving section and the nature of the rock, the number and size of the boom are different. The boom is responsible for supporting, advancing, and moving the corresponding level of rock drill. According to the different level of automation, it can be roughly divided into two categories: ordinary emulsion pump station (hydraulic manual control) and rock drilling robot (computer control).

This study summarizes the application status of the emulsion pump station in domestic metal mines and coal mines and quantitatively evaluates the technical advantages of the emulsion pump station in drilling accuracy, drilling efficiency, personnel safety, environmental protection index, etc. The initial friction coefficient of drawing fluid A lubrication is 0.21 , and then, with the extension of time, the friction coefficient gradually decreases to 0.14 . The initial friction coefficient of drawing fluid $\mathrm{B}$ is 0.22 , then it decreases rapidly to 0.13 , then it is stable at 0.17 , and then it remains basically unchanged. When the temperature is $55^{\circ} \mathrm{C}$, the initial friction coefficient is 0.16 and then decreases to 0.12 . Therefore, the frequency conversion constant pressure control system of the mine emulsion pump station should be selected according to the environment and application scenarios.

Generally speaking, the emulsion pump station is mainly driven by the hydraulic system. The common emulsion pump station realizes the movement of the drill arm and the normal operation of the rock drill by manually controlling the valve group. The rock drilling robot can send instructions to the control system through the human-computer interaction platform to realize the automatic positioning and automatic drilling of blast hole, with less manual intervention, which is the development direction of rock drilling and blasting in the future. The dynamic balance test of motor rotor in the emulsion pump station is a key link in the commissioning process of motor. The key lies in the determination of unbalance quality and angle. The vector method is applied to the dynamic balance field test of the motor rotor of the emulsion pump station of the compressor station and effectively solves the problem of high vibration of the motor after field installation. It quickly and effectively detects rotor imbalances, reducing counterweight addition time and effectively improving balance accuracy. By summarizing the problems encountered in the process of motor production and the treatment methods, we can accumulate relevant data and experience for the compressor station motor production, which can not only promote the smooth completion of the compressor station equipment production but also ensure the reliability and stability of the motor in the process of production and operation.

\section{Data Availability}

No data were used to support this study.

\section{Conflicts of Interest}

The authors declare that they have no conflicts of interest.

\section{Acknowledgments}

This work was supported by 2020 Special Foundation Project of Fundamental Scientific Research Professional Expenses for Undergraduate Universities in Heilongjiang Province (Grant No. 2020-KYYWF-0516). The name of the project is "Study on optimization of variable frequency and constant pressure control system for mine emulsion pump station." This work was also supported by the key entrustment project of research on the Teaching Reform of Higher Education in Heilongjiang Province (Grant No. SJGZ20170038), with the name "Research and practice on the training mode of characteristic technical talents in coal-electricity electrical engineering and automation." This research work was funded by the Key Discipline Construction Funds of Heilongiiang University of Technology. The support of the Natural Science Foundation of Heilongjiang Province of China (Grant No. LH2020C091) is gratefully acknowledged.

\section{References}

[1] V. P. Povarov, O. V. Urazov, M. B. Bakirov, S. S. Pakhomov, and I. A. Belunik, "Restoration of metal properties of circulation pump blades by the method of surface ultrasonic impact treatment," Thermal Engineering, vol. 64, no. 10, pp. 762-769, 2017.

[2] Y. Lin, W. Liang, Z. Qiu et al., "A new state evaluation method of oil pump unit based on AHP and FCE," Journal of Physics: Conference Series, vol. 842, no. 1, pp. 126-130, 2017.

[3] E. Zapolnova, T. Golz, R. Pan, K. Klose, S. Schreiber, and N. Stojanovic, "THz pulse doubler at FLASH: double pulses for pump-probe experiments at X-ray FELs," Journal of Synchrotron Radiation, vol. 25, no. 1, pp. 39-43, 2018.

[4] Y.-K. Park, Y.-H. Choi, J.-W. Han, Y. Jung, H. Kim, and Y.-W. Lee, "Study on vortex control around pump intake in a circular pump station," Transactions of the Korean Society of Mechanical Engineers-B, vol. 42, no. 1, pp. 27-33, 2018.

[5] J. Weinrich, T. Labrie, and E. Walsh, "Restoring flood resiliency with a flood pump station rehabilitation in Lowell," The NEWEA Journal, vol. 53, no. 1, pp. 18-25, 2019.

[6] G. Davies, K. Watson, B. Bodniewicz, D. Dandach, S. Kharkar, and N. Passarelli, "Challenges for design and constructability of tunnel dewatering pump stations," Proceedings of the Water Environment Federation, vol. 2017, no. 9, pp. 3233-3240, 2017.

[7] L. Wang, Q. Han, D. Chen, C. Wu, and X. Wang, "Non-linear modelling and stability analysis of the PTGS at pump mode," 
Iet Renewable Power Generation, vol. 11, no. 6, pp. 827-836, 2017.

[8] H.-J. Kim, S. W. Park, and D. S. Rhee, "Numerical analysis of the effects of Anti-vortex Device height on hydraulic performance of pump sump," Ksce Journal of Civil Engineering, vol. 21, no. 4, pp. 1484-1492, 2017.

[9] S. J. Ohrem and C. Holden, "Modeling and nonlinear model predictive control of a subsea pump station," IFAC-PapersOnLine, vol. 50, no. 2, pp. 121-126, 2017.

[10] J. Landers, "CSO program in evansville, Indiana, marks key milestone with start of pump station construction," Civil Engineering, vol. 89, no. 2, pp. 27-29, 2019.

[11] E. A. Muravyova, A. V. Bondarev, M. I. Sharipov et al., "Power consumption analysis of pump station control systems based on fuzzy controllers with discrete terms in iThink software," IOP Conference Series Materials Science and Engineering, vol. 327, no. 2, pp. 22-27, 2018.

[12] H. A. Hussein, A. J. Aleeby, and Z. M. Mahdi, "Improving the performance of the pump station in pipe line transportation system using PLC controller and remote monitoring," IOP Conference Series: Materials Science and Engineering, vol. 765, no. 1, pp. 125-132, 2020.

[13] V. N. Stepanov, S. O. Kireev, M. V. Korchagina, and A. V. Efimov, "Analysis of efficiency of a system for heating the water-supply pump and high-pressure pump of a pumping station from the exhaust gases of an internal combustion engine," Chemical and Petroleum Engineering, vol. 55, no. 9-10, pp. 829-834, 2020.

[14] S. Liang, X. Zhao, and L. I. Sheng, "The application of GMS in numerical simulation of groundwater and faults disposing in gaizi river source," Advanced Materials Research, vol. 14, no. 2, pp. 20-24, 2020.

[15] C. Whelan and J. Karl, "FRAMES-2.0 software system: linking to the groundwater modeling system (GMS) RT3D and MT3DMS models," Technical Report, vol. 25, no. 4, pp. 58-62, 2019.

[16] X. Guo, "Application development of groundwater value simulation software in our country," Technical Report, vol. 32, no. 2, pp. 20-23, 2020.

[17] H. Shang, W. Wang, and J. Zhang, "Application of GMS in groundwater numerical simulation in the northern foot of Tianshan Mountain," Water Resource and Environmental Protection, vol. 20, no. 3, pp. 12-15, 2018.

[18] H. Ping-Hua, W. Xin-Yi, and H. Su-Min, "Recognition model of groundwater inrush source of coal mine: a case study on Jiaozuo coal mine in China," Arabian Journal of Geosciences, vol. 10, no. 15, pp. 323-329, 2017.

[19] Y. Wang, L. Cao, Y. Liu et al., "Evaluation of groundwater environmental quality in a mining area of Huaibei," Coalfield Geology and Exploration, vol. 39, no. 2, pp. 34-37, 2020.

[20] R. Tan, J. Gao, X. Zang et al., "The construction of threedimensional solid model of groundwater in GMS bedrock mining area," Groundwater, vol. 31, no. 6, pp. 15-17, 2020.

[21] Y. Fu, J. Du, Z. Mou et al., "Mine water inflow prediction method based on underground water cut system in coal minewater release-section flow method," Coal Geology of China, vol. 9, no. 30, pp. 37-43, 2018.

[22] H. Kang and Y. Feng, "Monitoring of stress change in coal seam caused by directional hydraulic fracturing in working face with strong roof and its evolution," Journal of China Coal Society, vol. 37, no. 12, pp. 1953-1959, 2020.

[23] R. Li, "Intelligent fluid supply technology in fully-mechanized coal mining face and its development trend," Coal Science and Technology, vol. 47, no. 9, pp. 203-207, 2019.
[24] R. Li, "Research and development as well as application of high pressure and high flow emulsion pump to large mining height face," Coal Science and Technology, vol. 45, no. 12, pp. 145-149, 2017.

[25] J. Blunschi, J. Wang, and T. Ertekin, "Hydraulic fracturing mechanisms in coal: a review," International Journal of Oil, Gas and Coal Technology, vol. 14, no. 3, pp. 18-26, 2017. 